\title{
Seismic retrofit of $\mathrm{RC}$ beam-column joints using the
}

\section{MF-EBR strengthening technique}

\author{
Mário Coelho ${ }^{1, a}$, Pedro Fernandes ${ }^{1, b}$, José Melo ${ }^{2, c}$, José Sena-Cruz ${ }^{1, d}$, \\ Humberto Varum ${ }^{2, \mathrm{e}}$, Joaquim Barros ${ }^{1, \mathrm{f}}$ and Aníbal Costa ${ }^{2, \mathrm{~g}}$ \\ ${ }^{1}$ ISISE, University of Minho, School of Engineering, Department of Civil Engineering, \\ Azurém, 4800-058 Guimarães, Portugal \\ ${ }^{2}$ University of Aveiro, Department of Civil Engineering, Santiago, \\ 3810-193 Aveiro, Portugal \\ amcoelho@civil.uminho.pt, ${ }^{b}$ pfernandes@civil.uminho.pt, ${ }^{c}$ josemelo@ua.pt, \\ disena@civil.uminho.pt, ${ }^{\mathrm{e}}$ hvarum@ua.pt, ${ }^{\mathrm{f}}$ barros@civil.uminho.pt, ${ }^{\mathrm{g}}$ agc@ua.pt
}

Keywords: multi-directional CFRP laminates; RC beam-column joint; seismic strengthening; MF-EBR strengthening technique.

\begin{abstract}
The strengthening technique based on the application of multi-directional laminates of CFRP (MDL-CFRP) simultaneously glued and anchored to the surface of the elements to be strengthened has been recently proposed. This technique was designated Mechanically Fastened and Externally Bonded Reinforcement (MF-EBR) and combines the fasteners from the MF-FRP technique with the externally glued properties from the EBR. With the aim of assessing the potentialities of this technique for seismic retrofitting, three interior $\mathrm{RC}$ beam-column joints were strengthened according to the MF-EBR technique and tested. This work presents the entire test program executed, including test configuration, results and corresponding analysis.
\end{abstract}

\section{Introduction}

The main existent techniques for repair and strengthen reinforced concrete (RC) beam-column joints can be grouped as follows: repair with epoxy (injection of epoxy resin in the cracks of lightly degraded elements); removal and replacement of concrete in more damaged areas; jacketing with RC layers, masonry blocks or steel plates; use of composite materials. Epoxy repair techniques have exhibited limited success, whereas concrete jacketing of columns and encasing the joint region is an effective but the most labor-intensive strengthening method [1]. Externally bonded FRP composites can eliminate some important limitations of other methods such as difficulties during the strengthening work and the final size of the members [1].

Recently, a repair and strengthening technique that uses multi-directional carbon fiber laminates (MDL-CFRP), simultaneously glued and anchored to concrete, called Mechanically Fastened and Externally Bonded Reinforcement (MF-EBR) was proposed [2]. To assess the potentialities of this technique for seismic retrofitting, three interior RC beam-column joints were strengthened according to the MF-EBR 
technique and tested. In this paper the tests are described and the results are presented and discussed.

\section{Experimental Program}

Fig. 1 presents the geometry of the joints, as well as the cross sections of the beam and column adopted for all the specimens. In the beams, with $0.30 \mathrm{~m}$ wide and $0.40 \mathrm{~m}$ height, the longitudinal reinforcement was composed of 2 steel bars of $12 \mathrm{~mm}$ diameter $(2 \varnothing 12)$ at the top and $4 \varnothing 12$ at the bottom. The transverse reinforcement consisted in $8 \mathrm{~mm}$ stirrups spaced $0.20 \mathrm{~m}$. In the columns, with square cross-section of $0.30 \mathrm{~m}$ edge, the longitudinal reinforcement was composed of $4 \varnothing 12$ and the transverse reinforcement was formed by $8 \mathrm{~mm}$ stirrups spaced at $0.25 \mathrm{~m}$. The concrete cover was $2 \mathrm{~cm}$ thick for all the elements (beams and columns).
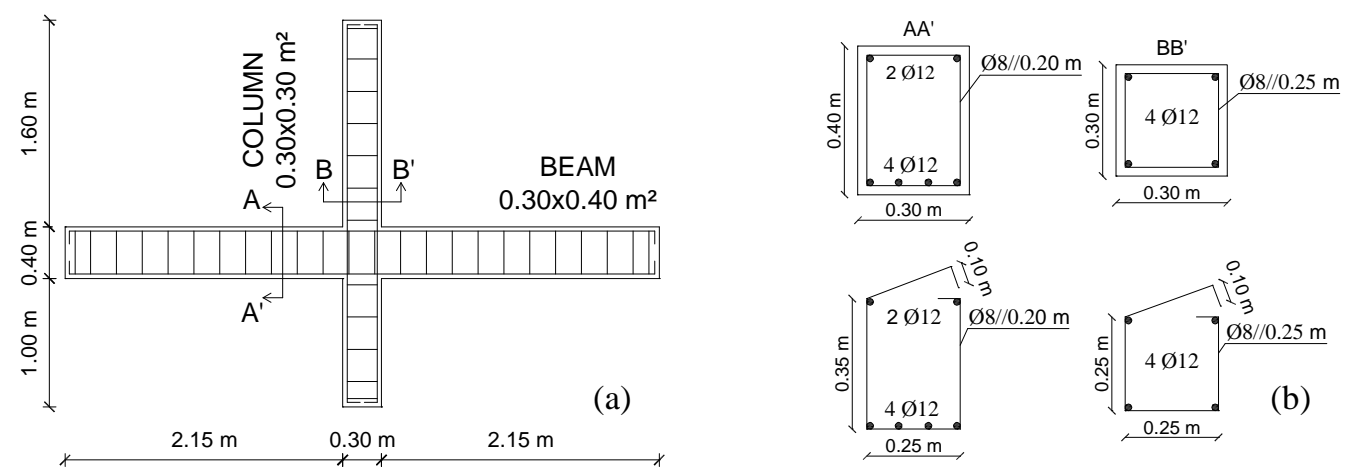

Figure 1: Geometry and detailing of reinforcement: $(a)$ joint; $(b)$ cross sections of the beams and columns.

Fig. 2 presents the adopted test setup and the corresponding instrumentation. The transverse and axial loads at the top of the "upper column" were applied by two hydraulic servo-controlled actuators equipped with two load cells C1 and C2 (see Fig. 2a) two measure the corresponding forces. Additionally, one load cell (C3 in Fig. 2a) was used to register the horizontal reaction at the base of the column and another one to register the vertical reaction at the same point (C4 in Fig. 2a). Several linear variable differential transducers and inductive linear position sensors were used to measure the displacements along the specimen (see Fig. 2b). Further details about the test configuration and instrumentation can be found elsewhere [3].
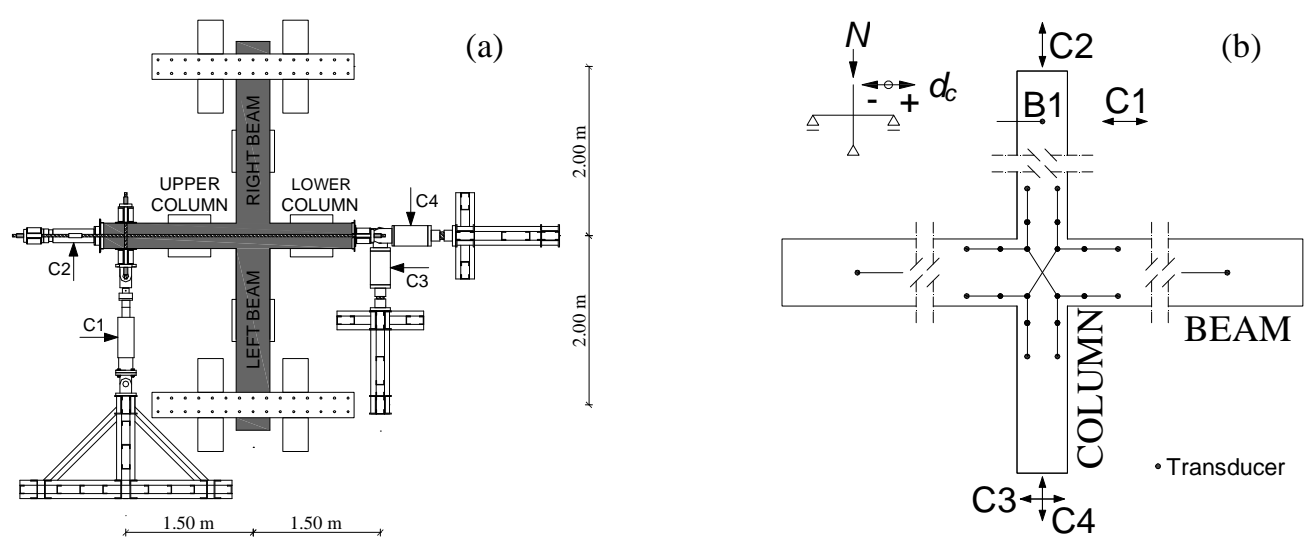

Figure 2: (a) test setup; (b) instrumentation. 
All the tests were carried out under displacement control at B1 (see Fig. 2b). The imposed law consisted on applying complete cycles with signal inversion throughout eighteen displacement levels with growing amplitude. The levels chosen were $\pm 1 \mathrm{~mm}$, $\pm 2 \mathrm{~mm}, \pm 4 \mathrm{~mm}, \pm 6 \mathrm{~mm}, \pm 10 \mathrm{~mm}, \pm 15 \mathrm{~mm}, \pm 20 \mathrm{~mm}, \pm 25 \mathrm{~mm}, \pm 30 \mathrm{~mm}, \pm 40 \mathrm{~mm}$, $\pm 50 \mathrm{~mm}, \pm 60 \mathrm{~mm}, \pm 70 \mathrm{~mm}, \pm 80 \mathrm{~mm}, \pm 90 \mathrm{~mm}, \pm 100 \mathrm{~mm}, \pm 110 \mathrm{~mm}$ and $\pm 120 \mathrm{~mm}$. From level $\pm 1 \mathrm{~mm}$ to $\pm 4 \mathrm{~mm}$ only one complete cycle per level was performed. From level $\pm 6 \mathrm{~mm}$ to the end of the test three complete cycles per level were applied.

The experimental program was developed in two distinct phases. Initially, the three joints were submitted to a cyclic loading in order to cause a level of damage similar to a seismic event. All the details about this phase can be found elsewhere [4]. In the second phase, all the joints were strengthened with MDL-CFRP according to the strengthening solutions defined in Fig. 3. In this phase, the joints initially denominated by JD, JPA-1 and JPA-2, were designated by JDR, JPA-1R and JPA-2R.

In both phases, before the cyclic test began, an axial force of $200 \mathrm{kN}$ was applied at the top of the column. This force corresponds to a reduced axial force (v) of about $10 \%$ which is a typical value for columns in buildings with 2-3 floors and spans with approximately $4 \mathrm{~m}$. That force remains constant during the entire test of all the specimens
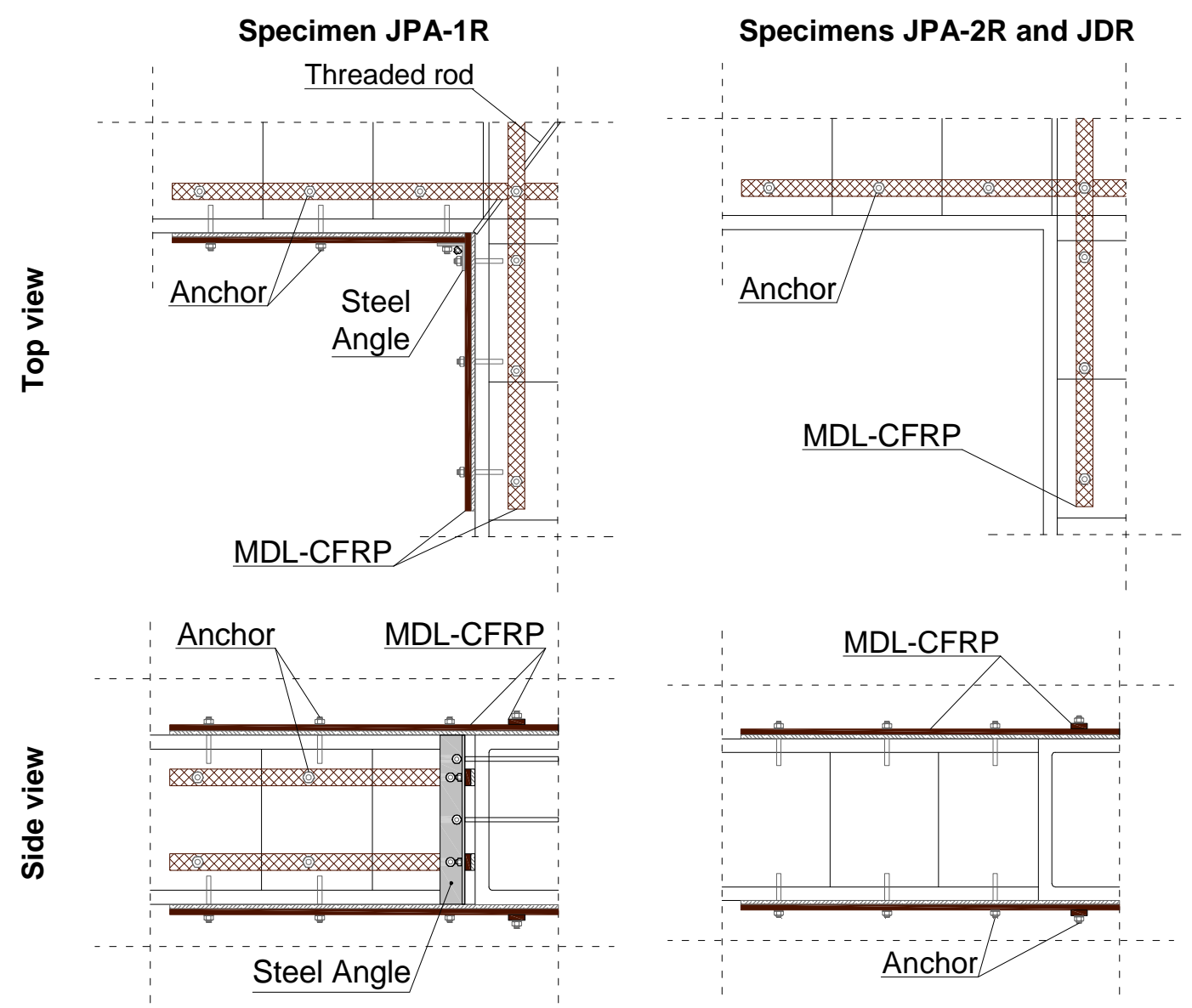

Figure 3: Strengthening solutions adopted in the context of the present work. 


\section{Material Characterization}

The concrete used in this work was characterized by means of compression tests with cubic concrete specimens (15 cm wide). An average compressive strength of 23.5 MPa was obtained, which corresponds to a characteristic compressive strength of 19.5 MPa, according to the EN 206-1:2000 + A1:2004 (PT).

The mechanical properties of the plain rebars (specimens JPA-1, JPA-2, JPA-1R and JPA-2R) were evaluated by executing tensile tests according to EN 10002-1:1990 (PT). From the tensile tests an average value of $590 \mathrm{MPa}, 640 \mathrm{MPa}$ and $198 \mathrm{GPa}$ was obtained for the yielding and ultimate stresses, and for the Young modulus, respectively. The ribbed rebars properties (specimens JD and JDR) were assumed equal to those of normal A400 NR construction steel (NP EN 1992-1-1:2010).

The MDL-CFRP used to strengthen the joints was designed and produced in the scope of the current research project. All the information related to its development and characterization can be consulted elsewhere [2]. From this characterization the following main average values were obtained: tensile strength of $1866 \mathrm{MPa}$; modulus of elasticity of $118 \mathrm{MPa}$; strain at failure of $1.58 \%$; bearing unclamped resistance of $316 \mathrm{MPa}$; bearing clamped resistance of $604 \mathrm{MPa}$; thickness of $2.07 \mathrm{~mm}$.

The S\&P Resin 220 epoxy adhesive® was selected to glue the MDL-CFRP to concrete. To mechanically fix the MDL-CFRP to concrete a Hilti solution composed by the resin HIT-HY 150 MAX, the HIT-V M8 8.8 threaded anchors and DIN 9021 washers was adopted. The anchors were pre-stressed using a torque of $40 \mathrm{~N} \cdot \mathrm{m}$. The main characteristics of these materials can be found elsewhere [2].

\section{Preparation of the Specimens}

The preparation of the joints involved three main steps: joint reconstruction, crack sealing and MDL-CFRP application. All the details about these steps can be found in [3].

\section{Results}

Fig. 4 presents for all the specimens the relationship between the horizontal displacements at the top of the column (B1 - see Fig. 2b) versus lateral forces ( $\mathrm{C} 1$ see Fig. 2a) and corresponding envelopes. Table 1 presents the main results obtained in terms of maximum force reached (in both directions) for the original (JD, JPA-1 and JPA-2) and strengthened specimens (JDR, JPA-1R and JPA-2R).

As it can be seen, for the JDR and JPA-1R joints the adopted repair/strengthening strategy provided an increase of load carrying capacity, when compared with the reference damaged specimens. In fact was an increase of about $10 \%$ and $35 \%$ was obtained for the JDR and JPA-1R specimens, respectively. The strengthening strategy applied in the damaged JPA-2R specimen, only restored the stiffness and the load carrying capacity of the original JPA specimen, which still is, however, notable, taking into account the level of damage installed. 

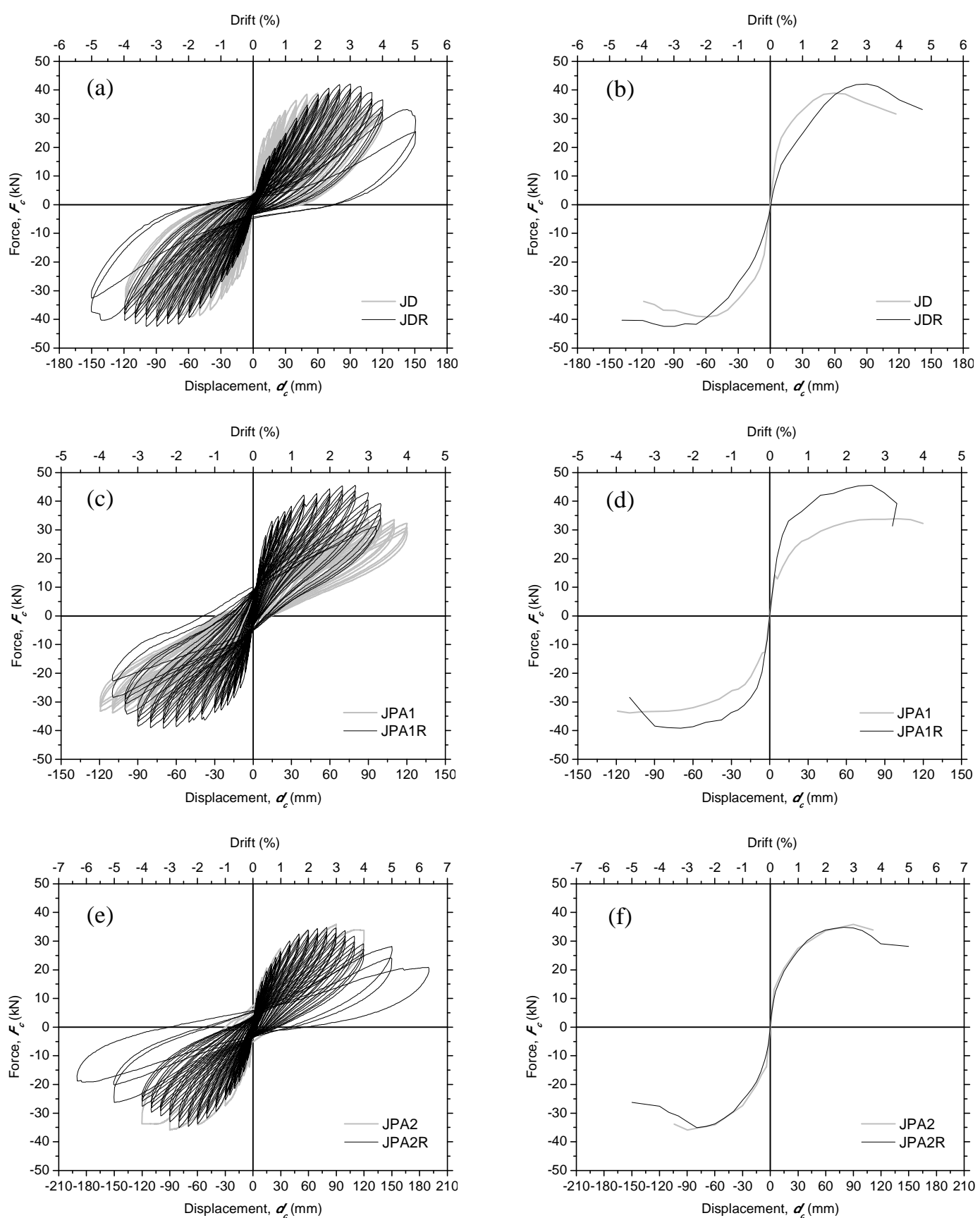

Figure 4: Force vs. displacement registered by load cell C1: (a) JD and JDR; (b) JD and JDR envelopes; (c) JPA-1 and JPA-1R; (d) JPA-1 and JPA-1R envelopes;

(e) JPA-2 and JPA-2R; (f) JPA-2 and JPA-2R envelopes.

When, for each joint, the envelopes of the curves are compared, two distinct responses can be pointed out. In JPA-1R and JPA-2R the initial stiffness was recovered. This was not observed in JDR, which can be justified by the repairing technique adopted. In fact, for the case of the specimens with plain rebars, in addition to the concrete spalling at the corners of the joint, only one large single crack was observed. These two main damages were easily detected and repaired. However for the case of the JDR with ribbed rebars, in addition to the concrete crushing, several 
cracks with distinct widths occurred in the first phase of tests. In this case the crack sealing strategy has been unable of restoring the integrity of the original joint.

Failure modes of the joints include basically flexural cracks and concrete spalling at the corners of the joints. When comparing the level of these damages, JPA-2R presented a high level of concrete spalling at the corners of the joint. This behavior can justify the smaller performance of the strengthening strategy in this specimen. On the other hand, the use of diagonal threaded rods (see Fig. 3) may have contributed for the delay of concrete spalling, justifying the best performance of JPA-1R.

Table 1: Main results obtained.

\begin{tabular}{ccccc}
\hline \multirow{2}{*}{ Specimen } & \multicolumn{2}{c}{ Negative direction } & \multicolumn{2}{c}{ Positive direction } \\
& $F_{\mathrm{c}, \max }[\mathrm{kN}]$ & Cycle & $F_{\mathrm{c}, \max }[\mathrm{kN}]$ & Cycle \\
\hline JD & -39.14 & 60 & 38.9 & 60 \\
JDR & $-42.48(9 \%)$ & 100 & $42.11(8 \%)$ & 90 \\
\hline JPA-1 & -33.85 & 110 & 33.85 & 100 \\
JPA-1R & $-39.22(16 \%)$ & 70 & $45.54(35 \%)$ & 80 \\
\hline JPA-2 & -35.85 & 90 & 35.84 & 90 \\
JPA-2R & $-35.06(-2 \%)$ & 80 & $34.78(-3 \%)$ & 80 \\
\hline
\end{tabular}

Note: Values in parentheses are the strength increment value when compared with the un-strengthened.

\section{Conclusions}

In the present work three intensively damaged RC beam-column joints were strengthened using the MF-EBR strengthening technique. The increase level of load carrying capacity depends on the specificities adopted for the strengthening strategy, and a maximum increase of $35 \%$ was attained.

\section{Acknowledgements}

This work is supported by FEDER funds through the Operational Program for Competitiveness Factors - COMPETE and National Funds through FCT - Portuguese Foundation for Science and Technology under the project PTDC/ECM/74337/2006. The authors acknowledge the materials generously supplied by Hilti Portugal Productos e Serviços Lda., S\&P Clever Reinforcement Ibérica Lda. and SECIL.

\section{References}

[1] M. Engindeniz, L.F. Kahn, A.H. Zureick: ACI Structural Journal, Vol. 102, No. 2, (2005), p. 1-14.

[2] J.M. Sena-Cruz, J.A.O. Barros, M.R.F. Coelho: Adv. Mater. Res. Vols.133-134, (2010), p. 917-922.

[3] M. Coelho, P. Fernandes, J. Melo, J. Sena-Cruz, H. Varum, J. Barros, A. Costa: Seismic strengthening of beam-column joints with multi-directional CFRP laminates (Report no. 11-DEC/E-13), University of Minho, (2011), 47 pp. 
[4] C. Fernandes, J. Melo, H. Varum, A. Costa: Journal of IBRACON de Estruturas e Materiais, RIEM, Vol. 4, Num. 1, (2011), p. 147-172. 